\title{
A Note on Place Names
}

For all cities and countries, I use the English translation - Cologne, for instance, instead of Köln (see figure 0.1). For Chemnitz, which the East German government renamed Karl-Marx-Stadt in 1953 and which regained its former name after Germany's reunification, I use KarlMarx-City. Municipal addresses, on the other hand, I leave untranslated (see figure 0.2). Street names such as Schönhauser Allee, which in English would be "Schönhaus Boulevard," or Alexanderplatz, which would be "Alexander Plaza," I render in the original German. 
This page intentionally left blank 